1985 House of Lords ruling in Gillick $v$ DHSS, which still holds good today, may serve to remind doctors of the duty they owe to parents and to their profession

Lord Justice Fraser: "Nobody doubts that in the overwhelming majority of cases the best judges of a child's welfare are his or her parents. Nor do I doubt that any important medical treatment of a child under 16 would normally only be carried out with the parent's approval. That is why it would and should be 'most unusual' for a doctor to advise a child without the knowledge and consent of the parents on contraceptive matters."

Lord Justice Scarman: "I accept that great responsibilities will lie on the medical profession. It is however a learned and highly trained profession, regulated by statute and governed by a strict ethical code which is vigorously enforced. Abuse of the power to prescribe contraceptive treatment for girls under the age of 16 would render a doctor liable to severe professional penalty."

VICTORIA GILLICK

Wisbech,

Cambridgeshire PE13 1N]

1 Confidentiality and people under 16. London: British Medical Association, General Medical Services, Committee, Health Association, General Medical Sevises, Conmittee, Health Education Authority, Brook Advisory Centres, Family 1993.

2 Scally G. Confidentiality, contraception, and young people. $B M \% ; 307: 1157-8$. (6 November)

3 Roberts J. GPs are deeply divided over pill for under-16s. Pulse 1985;45:5 Jan.

\section{Migraine and risk of ischaemic stroke}

EditoR,-According to Claire Morton, Christophe Tzourio and colleagues found no overall association between migraine and ischaemic stroke. $^{2}$

In our case-control study of cerebral ischaemia we recruited 308 young adults (135 with transient ischaemic attack and 173 with stroke) and 591 controls and showed a significant association between cerebral ischaemia and migraine with aura in the medical history (odds ratio $5.2 ; \mathrm{P}=0.016$ ) in patients under $45 .^{3}$ The odds ratio increased to 14.8 after adjustment for other vascular risk factors, carotid lesions, and cardiac diseases. Odds ratios were higher in the subgroup of patients with stroke at entry $(8.6 ; P=0.05)$ than in the patients with transient ischaemic attack $(3 \cdot 0 ; P=0.21)$. Consequently, the negative overall result in the study of Tzourio and colleagues does not seem to be attributable, as Morton claims, to the exclusion of those patients with stroke (mostly transient ischaemic attack in our opinion) well enough to remain at home.

In our study the risk of stroke associated with migraine was evident both in patients aged under 35 and in those aged 35-44, with a higher odds ratio in patients under $35(10.6 ; P=0.03)$ despite a similar prevalence of migraine with aura in patients over and under $35(2 \cdot 4 \% v 2 \cdot 7 \%)$. This dependence of the risk on age may be another explanation for the significant association between migraine and ischaemic stroke in women under 45 reported by Tzourio and colleagues.

Morton's second observation, concerning the vascular territory affected in migraine sufferers, also seems questionable. Broderick and Swanson refer to cases of migrainous stroke, a clinical entity different from ischaemic stroke occurring in patients with a history of migraine. ${ }^{4}$

In our study the carotid territory was affected in three quarters of patients with coexisting stroke and migraine with aura in their medical history. Two patients had an occlusion of the distal branches of the middle cerebral artery, and one had fibromuscular dysplasia of the common carotid artery.
One patient had a cerebral infarction in the left occipital lobe with occlusion of the corresponding posterior cerebral artery. These findings are consistent with most of the proposed mechanisms for stroke related to migraine. ${ }^{5}$

A CAROLEI

C MARINI

C FIESCHI

and the

NATIONAL RESEARCH COUNCIL STUDY GROUP

\section{Clinica Neurologica,}

Dipartimento di Medicina Interna e Sanità Pubblica,

Università degli Studi di L'Aquila

67100 L'Aquila-Collemaggio,

Italy

1 Morton C. Migraine and risk of stroke. BMF 1993;307:734 (18 September.)

2 Tzourio C, Iglesias S, Hubert J, Visy J, Alperovitch A Tehindrazanarivelo A, et al. Migraine and risk of ischaemic stroke: a case-control study. $B M F$ 1993;307:289-92. (31 July.)

3 Marini C, Carolei A, Roberts RS, Prencipe M, Gandolfo C Inzitari $\mathrm{D}$, et al. Focal cerebral ischemia in young adults: a collaborative case-control study. Neuroepidemiol 1993;12: 70-81.

4 Broderick J, Swanson J. Migraine related stroke. Clinical profile and prognosis in twenty patients. Arch Neurol 1987;44:868-71.

5 Olesen J, Welch KMA, Carolei A, Easton JD. Treatment to prevent migraine-related stroke. Cerebrovascular Diseases $1993 ; 3: 244-7$.

\section{Monovalent pertussis vaccine no longer available}

EDrror,-The BMf recently published two articles on pertussis vaccination. The first, on the national childhood encephalopathy study, reports that diphtheria, tetanus, and pertussis vaccine may, rarely, be associated with the development of severe acute neurological illnesses. ${ }^{1}$ The authors concluded (in agreement with the Department of Health's guidelines ${ }^{2}$ ), however, that "the balance of possible risk against known benefits from pertussis immunisation supports continued use of the vaccine."

The second article was David Miller's review of a television documentary programme about batches of pertussis vaccine in the $1960 \mathrm{~s}$ and $1970 \mathrm{~s}$ that were a possible cause of brain damage in some cases. $^{3}$ Again, though, the message was that pertussis vaccination was to be recommended for most children.

Neither article mentioned, however, that the manufacturers no longer produce monovalen pertussis vaccine. Owing to lack of demand pertussis vaccine is now available only with diphtheria and tetanus vaccine. If parents do not want their child to receive pertussis vaccine, or are advised against it, a course of diphtheria and tetanus vaccine is given (three doses, at 2,3 , and 4 months). If the situation then changes (for example, parents change their minds) and a further three doses of diphtheria and tetanus vaccine are given with the pertussis vaccination there is a risk of severe local reactions to the tetanus vaccine.

This means that, before any injections are given, parents considering not having their child vaccinated against pertussis must be counselled. All general practitioners, health visitors, practice nurses, and community and hospital paediatricians should be aware of this change. Parents should be told both of this change and of the statistics on the risks and benefits of the vaccination.

R JOYCE

Department of Community Paediatrics,

Livingstone Hospital,

Dartord,

Kent DA1 1SA

1 Miller D, Madge N, Diamond J, Wadsworth J, Ross E. Pertussis immunisation and serious acute neurological illnesses in children. BMF 1993;307:1171-5. (6 November.)

2 Department of Health. Immunisation against infectious disease. London: HMSO, 1993.

Miller D. Pertussis vaccine under scrutiny. BMf 1993;307:1430. (27 November.)

\section{Mortality and morbidity after hip fractures}

EDITOR,-Graham Keene and colleagues once again highlight the considerable morbidity and mortality attached to proximal femoral fracture, particularly in those patients with extracapsular fractures. ${ }^{1}$ The two year difference in mean age between patients with extracapsular fracture $(80$ years) and intracapsular fracture (78 years) is clinically important and presumably statistically significant, although this is not reported. A significant four year difference in the age of elderly women (aged 65 and over) with extracapsular or intracapsular fractures in Belfast has been reported, but there were no significant differences in mortality between cervical and trochanteric fractures within age groups. ${ }^{2}$ In Newcastle, when age was taken into account there was no difference in the fatality of trochanteric and cervical fractures. ${ }^{3}$

The high mortality of hip fracture is starkly highlighted by rates of $28 \%$ at six months and $33 \%$ at one year. Similarly high values have been reported in elderly women in Belfast (mean age 81 years) who had a six month mortality of $29 \%$ and a one year mortality of $35 \%{ }^{4}$

It is important that the influence of age, sex, and domicile, in addition to other variables, is considered before comparisons between mortality and morbidity figures are made. A report from Belfast of a six month mortality of $15 \%$ suggests that not all elderly subjects with fractures were enrolled." Similarly low mortality may occur if studies include only elderly people residing in the community at the time of fracture, excluding the frail elderly in institutional, residential, and nursing home care. It is clear that if a purchasing authority seeks to compare measures of outcome and length of stay, or if comparitive audit is undertaken, the nature of the population and its selection must be clearly identified.

The continuing increase in the elderly proportion of the population will result in increasing numbers of hip fractures and attendant higher age related mortality and morbidity. Hospital care, outcome, and preventive measures need to be addressed from both a humanitarian and a financial perspective.

TRO BERINGER

Department of Health Care for the Elderly,

Royal Hospitals,

Belfast BT12 6BA

1 Keene GS, Parker MJ, Pryor GA. Mortality and morbidity after hip fractures. $B M 7$ 1993;307:1248-50. (13 November.)

2 Beringer TRO, McSherry DMG, Taggart HMcA. A microcomputer based audit of fracture of the proximal femur in the elderly. Age Ageing 1984;13:344-8.

3 Evans JG, Prudham D, Wandless I. A prospective study of fractured proximal femur: factors predisposing to survival. Age Ageing 1979;8:246-50.

4 Beringer TRO, Gilmore DH. Outcome following proximal femoral fracture in the elderly female. Ulster Med $f$ 1991;60:28-34.

Wallace RGH, Lowry JH, McLeod NW, Mollan RAB. A simple grading system to guide the prognosis after hip fracture in the elderly. $B M 7$ 1986;293:665.

\section{Managing stroke}

EDrToR,-Peter Sandercock promoted the establishment of stroke units and discussed the potential cost, suggesting that before hospitals initiated a specific stroke unit they should examine the costs and resources currently used.' During a seven month period we identified all patients admitted to our hospital with a diagnosis of stroke. Seventy nine patients ( 39 men, 40 women; mean (SD) age $73.8(8.8)$ years) were still in hospital two weeks after admission. They were assumed to be in need of further rehabilitation and included in a study.

We looked at the resources used by these patients in terms of bed days and average amount of treatment given to each patient. The mean (SD) 
length of stay was $30(30.5)$ days after entry to the study, and 2367 bed days ( $8 \%$ of the beds in the medical directorate) were used. For those treated the mean input per patient per weekday spen in hospital was 19.1 (9.9) minutes from physiotherapy, $15.3(12.2)$ minutes from occupational therapy, $13.2(7.9)$ minutes from speech therapy, and $4 \cdot 7$ (6) minutes from a dietitian.

We estimated that $10-12$ beds were required for stroke care in our 500 bed district general hospital, which serves a population of 138000 . Previous research suggests that stroke rehabilitation is most effectively provided by flexible use of beds in a rehabilitation ward rather than a demarcated unit. As a result of our study we have set up a stroke rehabilitation service, for patients of all ages, in an existing rehabilitation ward of a geriatric unit, and physiotherapy for patients with stroke has been increased. This has been achieved by reorganisation with no specific cost implications. We expect this reorganisation to improve medical management. In addition, we hope to improve outcome, as Kalra et al recently showed that a given amount of paramedical treatment is more effective in a stroke unit than a general medical ward ${ }^{3}$-perhaps because of the contribution made by functionally oriented nursing care. ${ }^{4}$ This kind of reorganisation, with no or minimal cost, to provide a stroke service might also be possible for other hospitals.

BRIGITTE YIP CHRISTINE H MCALPINE

Department of Geriatric Medicine, Stirling Royal Infirmary NHS Trust,

Stirling FK8 2AU

1 Sandercock P. Managing stroke-the way forward. BMF 1993; 307:1297-8. (20 November.)

2 Wade D. Organisation of stroke care services. Clin Rehabil 1989:3:227-33.

3 Kalra L, Dale P, Crome P. Improving stroke rehabilitation-a controlled study. Stroke 1993;24:1462-7.

4 Indredavik B, Bakke F, Solberg R, Rokseth R, Haaheim LI Holme I. Benefit of a stroke unit: a randomised controlled trial. Stroke 1991;22:1026-31.

\section{Acute respiratory distress syndrome}

EDrToR,-In their review of the acute respiratory distress syndrome Richard Beale and colleagues maintain that a pulmonary artery occlusion pressure of less than $18 \mathrm{~mm} \mathrm{Hg}$ is required to allow differentiation between the syndrome and pulmonary oedema secondary to acute heart failure and fluid overload. ${ }^{1}$ I would caution against using a specific pulmonary artery occlusion pressure to distinguish pulmonary oedema of cardiac origin from that due to increased permeability. At issue are not only the various technical factors involved in obtaining appropriate data with a pulmonary artery catheter but also the numerous physiological reasons that may render the pulmonary artery occlusion pressure an unreliable index of left atrial, and hence left ventricular, end diastolic pressure. ${ }^{2}$

Murray et al have proposed an expanded definition of the acute respiratory distress syndrome that excludes the pulmonary artery occlusion pressure as a diagnostic criterion. ${ }^{3}$ Their lung injury score incorporates the chest radiographic pattern, the severity of hypoxaemia as measured by the arterial oxygen tension and fractional concentration of inspired oxygen, the requirement for positive end expiratory pressure (for mechanically ventilated patients), and compliance of the respiratory system (when available). Murray et al provide a further argument against use of the pulmonary artery occlusion pressure to diagnose the acute respiratory distress syndrome. Because a pulmonary artery catheter is often inserted several hours after presentation the data obtained may not reflect the patient's initial haemodynamic profile. For example, a patient with pulmonary oedema due to transient left ventricular systolic dysfunction may have a normal pulmonary artery occlusion pressure after anti-ischaemic treatment has been started. Conversely, patients with the acute respiratory distress syndrome often undergo aggressive fluid resuscitation, resulting in a high pulmonary artery occlusion pressure at the initial measurement.

The use of a specific pulmonary artery occlusion pressure to differentiate between pulmonary oedema of cardiac origin and that due to increased permeability may lead to an incorrect diagnosis and therefore to inappropriate management of critically ill patients.

PETER V DICPINIGAITIS

Albert Einstein College of Medicine,

Bronx

NY 10461

USA

1 Beale R, Grover ER, Smithies M, Bihari D. Acute respiratory distress syndrome ("ARDS"): no more than a severe acute lung injury? BMF 1993;307:1335-9. (20 November.)

2 Raper R, Sibbald WJ. Misled by the wedge? The Swan-Ganz catheter and left ventricular preload. Chest 1986;89:427-34.

Murray JF, Matthay MA, Luce JM, Flick MR. An expanded definition of the adult respiratory distress syndrome. Am Rev Respir Dis 1988;138:720-3.

\section{Antibiotics and fatigue}

EDITOR,-It is bad enough when an unjustified conclusion slips past the gatekeepers, but when it is perpetrated by the editor himself ${ }^{1}$ one must protest. Jean-Francois Bergmann and his seven colleagues $^{2}$ have NOT shown that antibiotics do not cause fatigue, having only investigated amoxycillin versus placebo. ${ }^{2}$ They have not even succeeded in the hitherto impossible task of proving a negative, merely having failed to show that amoxycillin did "cause" fatigue in their sample of 79 healthy volunteers.

I concede, without waiting for the challenge, that I have no hypothesis as to why other antibiotics should differ from amoxycillin-but then, as there was no original hypothesis as to why amoxycillin was a prototypical antibiotic, I don't need one.

University of Wales College of Medicine,

M D VICKERS

Cardiff CF4 4XN

1 Antibiotics do not cause fatigue. [This week in BMJ]. $B M F$ 1993;307:unpaginated. (27 November.)

2 Bergmann J-F, Chassany O, Consoli SM, Buteau E, Bendjenana H, Le Mercier P, et al. Antibiotic induced fatigue. $B M f$ H, Le Mercier P, et al. Antibiotic
1993;307:1397-9. (27 November.)

\section{Purchasing decisions in the NHS}

\section{Made by managers ignorant of health care}

EDrToR,-I suggest that the reason why decisions on purchasing in the NHS are still not explicit three years after the introduction of the NHS reforms ${ }^{1}$ is that all too often those making the decisions are not appropriately qualified. On Thursday 18 November an advertisement appeared in the appointments section of the Times for a general manager for the Greater Glasgow Health Board. ${ }^{2}$ The advertisement pointed out that the board is one of the largest purchasers of health care in Britain with an annual expenditure in excess of $£ 750000000$. A brief description of the board and the position was followed by a stipulation of the qualifications required. Applicants were expected to be: "Already operating at head of a large organisation"; of "proven success in general management, finance and strategic planning; innovative with presence, flair and ability to communicate effectively at all levels, lead and manage change and develop people." The last sentence under the heading qualifications read "Experience of the NHS is not essential."

One week later the Times featured an advertisement for a general manager of manufacturing in a "high paced, high volume, high quality food manufacturing business" in the north of England. This advertisement also valued a "leadership style that generates continuous performance enhancement," but, in contrast to Glasgow Health Board, this company regarded experience at managerial level in a sizable food busines as essential.

It has yet to be proved that commercial style management is of any benefit to the delivery of health care in the NHS, but if we must mimic our industrial counterparts we should at least do it accurately. Surely no commercial institution would entrust a $£ 750000000$ budget to a manager, however charismatic, who did not have experience of the field of operation.

J G PALMER

Caldew Hospital

Carlisle CA2 5NW

1 Appleby J. NHS purchasing decisions are still not explicit. $B M \mathcal{F}$ 1993;307:1376. (27 November.)

2 Times (appointments section) 1993 Nov $18: 1$.

3 Times (appointments section) 1993 Nov 25:1.

\section{Target high spending areas for rationing}

EDrToR,-It is difficult to understand at a superficial level how, if all hospitals provided orthopaedic services at the national average cost, the NHS could achieve savings of over $£ 87 \mathrm{~m}$.' Assuming that the calculations by the Chartered Institute of Public Finance and Accountancy are correct, however, this represents quite a small saving if compared, for example, with recent expenditure on computer systems for the NHS. ${ }^{2}$ On a more serious note, John Appleby mentions various forms of plastic surgery and infertility treatment as targets for explicit rationing. ${ }^{1}$ If rationing or priority setting is about containing total spending on the NHS I find it surprising that the debate is concentrated on a few peripheral procedures; even if they were banned only minute overall savings would result.

It has been estimated that in the United States about half of the budget for Medicare (for the over $65 \mathrm{~s}$ ) is spent on the last few months of life. ${ }^{3}$ Any sensible debate on priority setting should address the political imperative of cost and tackle the high expenditure area of health care.

R P COLE

London SW14 7QF

1 Appleby J. NHS purchasing decisions are still not explicit. $B M \mathcal{f}$ 1993;307:1376. (27 November.)

2 Warden J. Managers put technology before patients, say MPs. BMF 1994;308:11-2. (1 January.)

3 Kitzhaber JA. Prioritising health services in an era of limits. $B M f$ 1993;307:373-7.

\section{Correction}

\section{War in Bosnia}

An editorial error occurred in this letter by Marijana Peruzović and Lucija Čikeš (2 October, p 872). The title should read "War in former Yugoslavia" (the letter does not relate to the war in Bosnia).

\section{Natural family planning}

An error occurred in the letter on natural family planning by John Kelly (20 November, p 1357). The last sentence of the penultimate paragraph should have read "The same issue quoted a recent analysis... which found a relative risk of 0.4 for people using condoms-that is, $40 \%$ [not $10 \%$, as published] of the risk for people not using condoms." 